\title{
Update on the Assessment of Severity and Management of Chronic Ischaemic Mitral Regurgitation
}

\author{
Dragoş Vinereanu, Andrea O Ciobanu
}

University of Medicine and Pharmacy Carol Davila, Bucharest, Romania

Department of Cardiology, University and Emergency Hospital of Bucharest, Romania

\section{ABSTRACT}

Ischaemic mitral regurgitation is a relatively common finding in patients with acute or chronic coronary disease, as a consequence of left ventricular remodelling. Irrespective of its severity, ischaemic mitral regurgitation is an independent predictor of cardiovascular events and death. In this review, we discuss the current recommendations for a comprehensive evaluation of mitral regurgitation mechanism and severity, using standard and novel imaging techniques, and also the most recent results from randomized trials regarding complex interventional and surgical treatment choices, according to specific mechanisms and patient characteristics.

Key words: mitral regurgitation, imaging, interventional treatment, surgery

\section{DEFINITION, CLASSIFICATION, AND PROGNOSIS}

Ischaemic mitral regurgitation (MR) is defined as MR occurring is the presence of coronary artery disease, most frequently an acute myocardial infarction (MI), associated with regional or global left ventricular (LV) pathological remodelling, in the presence of normal mitral leaflet morphology. (1)

Ischemic MR may be classified as acute or chronic. Acute ischaemic MR develops as a severe complication of $\mathrm{MI}$, due to papillary muscle rupture (a rare, but dramatic complication, with poor prognosis in the absence of emergency surgical correction) or severe papillary muscle ischaemia. Chronic ischaemic MR is associated with chronic coronary artery disease and results from regional or global LV remodelling. Regional LV dysfunction, which occurs more frequently in inferior or posterior $\mathrm{MI}$, leads to posteromedial papillary muscle displacement, chordal tethering, and asymmetrical restriction of the posterior mitral leaflet. Global LV dysfunction, which is commonly seen in dilated ischaemic LV, leads to subvalvular tethering of both papillary muscles and symmetrical restriction of the mitral leaflets.

Ischemic MR is a common finding following an acute MI. A community-based study identified ischaemic MR in $50 \%$ of patients who suffered a MI. Moderate-

\author{
Corresponding author: \\ Dragos Vinereanu \\ Professor of Cardiology and Internal \\ Medicine, Consultant, University of \\ Medicine and Pharmacy Carol Davila \\ Department of Cardiology \\ University and Emergency Hospital \\ 169 Splaiul Independentei, District 5, \\ 050098, Bucharest, Romania; \\ E-mail: vinereanu@gmail.com
}

Received: 20.03.2017

Accepted: 30.03.2017

Copyright (๑) Celsius Publishing House 
to-severe MR was reported in $10-12 \%$ of patients and was associated with a threefold increase in the risk of heart failure, and a 1.6 fold increase in death at 5year follow-up. (2) Furthermore, even mild MR was proved to be an independent predictor of cardiovascular events, with a twofold increase in the risk of death. $(3,4)$

\section{ECHOCARDIOGRAPHY FOR THE ASSESSMENT OF MECHANISMS AND SEVERITY}

A comprehensive and careful echocardiographic assessment of the morphology and function of the mitral valve apparatus is crucial for understanding the mechanism, appreciate the severity, and decide upon the choice of correction of ischaemic MR. Current guidelines recommend assessment of mechanism and severity of ischaemic MR by two-dimensional (2D) echocardiography. However, three-dimensional (3D), transthoracic and transoesophageal, echocardiography has been suggested recently to provide additional useful information. (5-7)

Ischemic MR results from an imbalance between two types of forces, which normally lead to optimal coaptation and apposition of the mitral leaflets, as follows: (1) increased tethering forces, as a consequence of papillary muscle displacement, LV dilation, and mitral annular dilation; (2) decreased closing forces, as a consequence of LV and mitral annular dysfunction, as well as dyssynchrony of the LV and of the two papillary muscles. (8)

Echocardiographic examination should provide the following details regarding mechanisms and severity of ischaemic MR: (a) evidence for the ischaemic aetiology of MR (normal mitral leaflets or no significant intrinsic valve pathology, associated with regional or global LV dysfunction); (b) direction of the regurgitant jet (suggesting asymmetrical or symmetrical tethering of the mitral leaflets); (c) severity of the MR (by assessment of the vena contracta, effective regurgitant orifice area and regurgitant volume, and pulmonary systolic flow reversal); (d) impact on the LV function, left atrial (LA) dimension, and right heart dimensions and function.

Echocardiography provides important insights into the mechanisms of ischaemic MR, according to the site of MI. The most frequent pattern is an inferior or posterior MI. Posteromedial papillary muscle is more prone to ischemia, because of single vessel vascularisation (branches from the right coronary artery). In this case, echocardiography reveals hipo- or akinezia of the posteroinferior wall, with posterior displacement of the papillary muscle during systole, apical traction of the posterior mitral leaflet, which in turn leads to coaptation failure and asymmetrical apposition with the anterior mitral leaflet. Colour Doppler reveals a regurgitant jet, directed eccentrically, most often posteriorly. In contrast, anterolateral papillary muscle has double vascularisation provided by the left anterior descendent artery and marginal branches form the circumflex artery. Thus, the mechanism of ischaemic MR in anterior MI results from LV dilation and tethering of both papillary muscles during systole. Echocardiography shows symmetrical restriction of the mitral leaflets, secondary to LV enlargement and dysfunction, and more often a regurgitant jet orientated centrally. (1) In time, LV remodelling is followed by mitral annular dilation and progressive decrease of LV ejection fraction, leading to a vicious circle which worsens both the MR severity and LV dysfunction. (9)

Echocardiography is the main tool for assessment of the severity of ischaemic MR (table 1) (10). Current guidelines have set lower values for the severity of ischaemic MR, compared to degenerative MR, for two important reasons: firstly, 2D echocardiography may underestimate the severity of ischaemic MR, because of the eccentric jet and/or LV dysfunction; and secondly, patients with ischaemic MR have worse prognosis at a lower degree of MR, compared to those with degenerative MR, due to the ischaemic pathology and LV dysfunction. Additionally, several echocardiographic parameters, able to predict successful or failure of mitral repair, are recommended to be included in the preoperative assessment of ischaemic MR. (table 2) (10)

Transesophageal echocardiography plays an important role for patients with inappropriate transthoracic examinations, and for planning the surgical approach to mitral valve repair and perioperative assessment of patients undergoing different types of MR correction. Stress echocardiography may provide additional information. Thus, an increase of the regurgitant orifice area during exercise $>13 \mathrm{~mm}^{2}$ identifies patients with higher risk for cardiovascular events. (11) This reclassification of patients with resting mild to moderate MR to

Table 1 - Echocardiographic parameters for assessment of severity of ischemic mitral regurgitation (10)

\begin{tabular}{lc}
\hline Parameter & Severe ischaemic MR \\
\hline Vena contracta width & $\geq 7 \mathrm{~mm}$ \\
\hline Pulmonary vein flow & Systolic flow reversal \\
\hline Effective regurgitant orifice area & $\geq 0.2 \mathrm{~cm}^{2}$ \\
\hline Regurgitant volume & $\geq 30 \mathrm{ml} / \mathrm{beat}$ \\
\hline 3D echocardiography & Not validated yet \\
\hline
\end{tabular}


Table 2 - Echocardiographic parameters for preoperative prediction of unsuccessful mitral valve repair. (10)

\begin{tabular}{ll}
\hline Parameter & Value \\
\hline Coaptation distance & $>10 \mathrm{~mm}$ \\
\hline Systolic tenting area & $>2.5 \mathrm{~cm}^{2}$ \\
\hline Posterior mitral leaflet angle & $>45^{\circ}$ \\
\hline Anterior mitral leaflet angle & $>25^{\circ}$ \\
\hline Regurgitant jet & Central and/or complex jets \\
\hline Severe left ventricular dilation & - End-diastolic diameter $>65 \mathrm{~mm}$ \\
& - End-systolic diameter $>51 \mathrm{~mm}$ \\
Significant left ventricular & - End-systolic volume $>140 \mathrm{ml}$ \\
remodeling & - Systolic sphericity index $>0.7$ \\
& - End-systolic interpapillary \\
& distance $>20 \mathrm{~mm}$ \\
\hline
\end{tabular}

severe MR has important therapeutic impact.

Apart from echocardiography, there are other imaging methods that might provide important information for the assessment of patients with ischaemic MR. Cardiac magnetic resonance is an excellent method for the assessment of myocardial scar, MR severity, determination of LV volumes and ejection fraction, mainly when echocardiographic data are poor. (12) Coronary angiography is mandatory as part of the preoperative protocol. Ventriculography may be helpful for the assessment of MR severity and ejection fraction.

\section{TREATMENT - TECHNIQUES, GUIDELINES RECOMMENDATIONS, AND LATEST RESULTS}

The optimal management of ischaemic MR is still debated. Current guidelines and recent randomized trials focus on surgical and interventional options, addressing the mechanism of ischaemic MR, associated coronary vessel disease, and left ventricular dysfunction.

\section{Surgical treatment}

Although ischaemic MR increases mortality, there is conflicting evidence regarding survival improvement after mitral valve surgery. As expected, this observation created controversy in choosing the most appropriate correction approach. Current European and American guidelines have issued different recommendations for correction of ischaemic MR. The main difference is the absence of any class I recommendation for surgical treatment of ischaemic MR in the American guidelines (table 3). $(10,13)$

\section{Mitral valve repair}

The standard technique for mitral valve repair is restrictive annuloplasty, in order to correct the displaced posterior mitral annulus, increase leaflets coaptation, and improve mitral valve competence. It is a relatively simple procedure, used by most of the surgeons during CABG, with good results. However, at least $30 \%$ of

Table 3 - Current guidelines recommendations for surgery in chronic ischaemic mitral regurgitation (adapted from Vahanian et al 2012 and Nishimura et al 2017) $(10,13)$

\begin{tabular}{|c|c|}
\hline \multicolumn{2}{|l|}{ European Society of Cardiology/ European Association for Cardiothoracic Surgery } \\
\hline Recommendation & $\begin{array}{l}\text { ass of recommendation } \\
\text { and level of evidence }\end{array}$ \\
\hline Surgery is indicated in patients with severe MR undergoing CABG, and LVEF $>30 \%$ & I, C \\
\hline Surgery should be considered in patients with moderate MR undergoing CABG & Illa, C \\
\hline $\begin{array}{l}\text { Surgery should be considered in symptomatic patients with severe MR, LVEF }<30 \% \text {, } \\
\text { option for revascularization, and evidence of viability }\end{array}$ & Ila, C \\
\hline $\begin{array}{l}\text { Surgery may be considered in patients with severe MR, LVEF }>30 \% \text {, who remain symptomatic despite } \\
\text { optimal medical management (including CRT, if indicated) and have low comorbidity, when revascularization is not indicated }\end{array}$ & Ilb, C \\
\hline \multicolumn{2}{|l|}{ American College of Cardiology/ American Heart Association } \\
\hline $\begin{array}{l}\text { Mitral valve surgery is reasonable for patients with chronic severe secondary MR (stages } C \text { and } D \text { ) } \\
\text { who are undergoing CABG or AVR }\end{array}$ & Ila, C \\
\hline $\begin{array}{l}\text { It is reasonable to choose chordal-sparing MVR over downsized annuloplasty repair if operation is considered for severely } \\
\text { symptomatic patients (NYHA class III to IV) with chronic severe ischemic MR (stage D) and persistent symptoms despite } \\
\text { GDMT for HF }\end{array}$ & Ila, B-R \\
\hline $\begin{array}{l}\text { Mitral valve repair or replacement may be considered for severely symptomatic patients (NYHA class III to IV) } \\
\text { with chronic severe secondary (stage D) who have persistent symptoms despite optimal GDMT for HF }\end{array}$ & $\mathrm{llb}, \mathrm{B}$ \\
\hline In patients with chronic, moderate, ischemic MR (stage B) undergoing CABG, the usefulness of mitral valve repair is uncertain & Ilb, B-R \\
\hline
\end{tabular}


patients have recurrent MR at 30 days and up to $60 \%$ at 5 years, as a result of left ventricular remodelling and persistent subvalvular apparatus restriction. $(14,15)$ Therefore, new surgical techniques, addressing not only the mitral annulus but also the repair of the subvalvular apparatus have been developed. Chordal cutting is one of these techniques. Restrictive annuloplasty may cause increased tethering of the anterior mitral leaflet with paradoxical worsening of the ischaemic MR. Cutting a limited number of chordae attached to the base of the leaflet might result in releasing the tension, without inducing prolapse of the corresponding segment of the leaflet. In selected patients, this technique was showed to decrease recurrent ischaemic MR. (16)

\section{Papillary muscle relocation}

Papillary muscle relocation is another technique which may help restoration of the normal valvular geometry with release of the subvalvular tethering. In a recent study, patients receiving combined restrictive annuloplasty and papillary muscle relocation had lower rates of recurrent MR and fewer cardiovascular events at 5 years, compared to annuloplasty alone. (17)

Currently, MV repair is recommended for correction of severe ischaemic MR, if patient characteristics are favourable. However, there is no common agreement in patients with moderate ischaemic MR undergoing CABG. Recently, Michler et al randomized 301 patients with moderate ischaemic MR to CABG and MV repair or CABG alone. (18) At two years follow-up, there were no significant differences between groups for death and reverse LV remodelling, despite a higher rate of residual moderate or severe $M R$ in patients randomized to CABG alone ( $32 \%$ vs. $11 \%, p<0.001)$. However, patients who experienced a reduction in MR severity also showed improvement in regional and global LV function.

\section{Mitral valve replacement with chordal sparing}

The concept of preserving subvalvular apparatus during mitral valve replacement was first introduced in 1964, but reinforced by Tirone David in 1981, aiming to prevent postoperative left ventricular function deterioration. (19) The chordae and even the mitral valve may be sutured under the newly implanted prosthesis. Large anterior mitral leaflets can be removed, if needed. Mitral valve apparatus sparing reduces operative mortality, and may increase long-term survival compared to standard mitral valve replacement technique. (20)

Repair or replacement of mitral valve in patients with ischaemic MR is an ongoing controversy, as there are no clear recommendations in the current guide- lines. Acker et al randomized 251 patients with severe ischaemic MR to MV repair versus MV replacement with chordal sparing. At one year follow-up, there were no significant differences between groups for death, LV remodelling, major cardiovascular events or functional status, although moderate or severe MR recurrence was $33 \%$ in the repair group compared to $2 \%$ in the replacement group $(p<0.001)$. However, patients with a better MV repair experienced a significant improvement of LV end-systolic volume index, by comparison to patients with a less durable MV repair. Therefore, a more careful preoperative selection of patients, based on the parameters predictable for a successful repair, might identify those individuals who would benefit most from MV repair. (21)

\section{Interventional treatment (MitraClip technique)}

Patients with severe ischaemic MR and prohibitive surgical risk, who remain symptomatic despite maximal treatment, might benefit from interventional percutaneous mitral valve repair. This technique relies on a mechanical device delivered percutaneously into the left atrium, through an interatrial septal puncture. It grasps the mitral leaflets at the level of maximum regurgitant width, narrowing the regurgitant surface and reducing the severity of ischaemic MR. (22) The MitraClip technique proved to be safe and effective in the EVEREST II trial, which randomized patients with grade $3+$ and $4+M R$ and high surgical risk to either percutaneous repair or mitral valve surgery. Patients who underwent the interventional repair had less reduction of $\mathrm{MR}$ at discharge, and required more frequently surgery for residual MR during the first year compared to the surgical group. However, at five years follow-up, there was no worsening MR or need for surgery in the interventional arm, emphasising durability of the MitraClip. Also, despite more residual MR in the MitraClip arm, at five years there were no differences for long-term survival or LV function between the two treatment options. (23)

\section{Cardiac resynchronization therapy (CRT)}

Patients with persistent NYHA class III or IV symptoms despite maximal medical treatment, LBBB, and reduced LV ejection fraction T35\% are good candidates for resynchronization therapy. $(24,25)$ This technique may reduce $M R$ severity due to papillary muscle resynchronization and increased closing forces in the LV. In time, CRT favours LV remodelling and reduces tethering forces, resulting in improved mitral leaflets coaptation. $(26,27)$ vanBommel et al investigated the 
impact of resynchronization therapy on MR severity and prognosis in patients with ischemic dilated cardiomyopathy, moderate to severe $\mathrm{MR}$, and high surgical risk. There was at least 1 grade reduction in MR severity with CRT in $42 \%$ of patients. Moreover, MR improvement was an independent prognostic factor for survival. (28)

\section{CONCLUSION}

Chronic ischaemic mitral regurgitation is a frequent complication following an acute myocardial infarction or chronic coronary disease. Comprehensive characterization of its mechanisms and severity, using different imaging techniques, is crucial for an accurate assessment and optimal management, tailored for each patient.

\section{Conflict of interest: none.}

\section{REFERENCES}

1. Pierard LA, Carabello BA. Ischaemic mitral regurgitation: pathophysiology, outcomes and the conundrum of treatment. Eur Heart J. 2010 Dec 01;31(24):2996-3005.

2. Bursi F, Enriquez-Sarano M, Nkomo VT, Jacobsen SJ, Weston SA, Meverden RA, Roger VL. Heart failure and death after myocardial infarction in the community: the emerging role of mitral regurgitation. Circulation. 2005 Jan 25;111(3):295-301.

3. Rossi A, Dini FL, Fagiano P, Agricola E, Cicoira M, Frattini S, et al. Independent prognostic value of functional mitral regurgitation in patients with heart failure. A quantitative analysis of 1256 patients with ischemic and non-ischemic dilated cardiomyopathy. Heart. 2011 0ct;97(20):1675-80.

4. Grigioni F, Enriquez-Sarano M, Zehr KJ, Bailey KR, Tajik AJ. Ischemic mitral regurgitation: long-term outcome and prognostic implications with quantitative Doppler assessment. Circulation. 2001 Apr 3;103(13):1759-64.

5. Mihaila S, Muraru D, Piasentini E, Miglioranza MH, Peluso D, Cucchini $\mathrm{U}$, et al. Quantitative analysis of mitral annular geometry and function in healthy volunteers using transthoracic three-dimensional echocardiography. J Am Soc Echocardiogr. 2014 Aug;27(8):846-57.

6. Mihaila S, Muraru D, Miglioranza MH, Piasentini E, Aruta P, Cucchini $\mathrm{U}$, et. al. Relationship between mitral annulus function and mitral regurgitation severity and left atrial remodelling in patients with primary mitral regurgitation. Eur Heart J Cardiovasc Imaging. 2016 Jan 12;17(8):918-29.

7. Ciobanu AO, Griffin SC, Bennett S, Vinereanu D. Catastrophic mitral prosthesis dehiscence diagnosed by three-dimensional transesophageal echocardiography. J Clin Ultrasound. 2014 May 24;42(4): 249-51.

8. Lacellotti P, Marwick T, Pierard LA. How to manage ischaemic mitral regurgitation. Heart. 2008;94(11):1497-502.

9. Carabello BA. Ischemic mitral regurgitation and ventricular remodelling. J Am Coll Cardiol. 2004 Feb 4;43(3):384-5.

10. Vahanian A, Alfieri A, Andreotti F, Antunes MJ, Baron-Esquivias G, Baumgartner $\mathrm{H}$, et al. Guidelines on the management of valvular heart disease (version 2012): The Joint Task Force on the Management of Valvular Heart Disease of the European Society of Cardiology (ESC) and the European Association for Cardio-Thoracic Surgery (EACTS). Eur Heart J. 2012 Aug 24;33:2451-96.

11. Lancellotti P, Gerard PL, Pierard LA. Long-term outcome of patients with heart failure and dynamic functional mitral regurgitation. Eur
Heart J. 2005 Aug;26(15):1528-32.

12. Flynn M, Curtin R, Nowicki ER, Rajeswaran J, Flamm SD, Blackstone EH, Mihaljevic T. Regional wall motion abnormalities and scaring in severe functional ischemic mitral regurgitation: a pilot cardiovascular magnetic resonance imaging study. J Thorac Cardiovasc Surg. 2009 May;137:1063-70.e2.

13. 13. Nishimura RA, Otto CM, Bonow RO, Carabello BA, Erwin JP, Fleisher AL, et al. 2017 AHA/ACC Focused Update of the 2014 ACC/AHA Guideline for the Management of Patients With Valvular Heart Disease. A Report of the American College of Cardiology/American Heart Association Task Force on Practice Guidelines. J Am Coll Cardiol. 2017 Mar 10; 10.1016/j.jacc. 2017.03.011.

14. Grayburn PA, Foster E, Sangli C, Weissman NJ, Massaro J, Glower $D G$, et al. Relationship between the magnitude of reduction in mitral regurgitation severity and left ventricular and atrial reverse remodelling after MitraClip therapy. Circulation. 2013 0ct 8;128(15):1667-74.

15. Crestanello JA. Surgical approach to mitral regurgitation in chronic heart failure: when is it an option. Curr Heart Fail Rep. 2012 Mar;9(1): 40-50.

16. Messas E, Bel A, Szymanski C, Cohen I, Touchot B, Handschumacher $M D$, et al. Relief of mitral valve tethering following chronic myocardial infarction by chordal cutting diminishes left ventricular remodelling. Circ Cardiovasc Imaging. 2010 Nov 1;3(6):679-86

17. Calafiore AM, Refaie R, laco AL, Asif M, Al Shurafa HS, Al-Amri H, et al. Chordal cutting in ischemic mitral regurgitation: a propensitymatched study. J Thorac Cardiovasc Surg. 2014 Jul;148(1):41-6.

18. Michler RE, Smith PK, Parides MK, Ailawadi G, Thourani V, Moskowitz AJ, et al. Two-Year Outcomes of Surgical Treatment of Moderate Ischemic Mitral Regurgitation. N Engl J Med. 2016 May 19; 374 (20):1932-41.

19. David TE, Strauss HD, Mesher E, Anderson MJ, Macdonald IL, Buda AJ. Is it important to preserve the chorde tendinae and papillary muscles during mitral valve replacement? Can J Surg 1981 May; 24(3):236-9.

20. David TE. Ischemic Mitral Regurgitation: Chordal-Sparing Mitral Valve Replacement. Operative Techniques in Thoracic and Cardiovascular Surgery. 2012;17(3):194-203.

21. Acker MA, Parides MK, Perrault LP, Moskowitz AJ, Gelijns AC, Voisine $P$, et al. Mitral-valve repair versus replacement for severe ischemic regurgitation. N Engl J Med. 2014 Jan 2;370(1):23-32.

22. Ciobanu A, Bennett S, Azam M, Clark A, Vinereanu D. Incremental value of three-dimensional transoesophageal echocardiography for guiding double percutaneous MitraClip ® implantation in a 'no option' patient. Eur J Echocardiogr. 2011 Feb;12(2):E11.

23. Feldman T, Kar S, Elmariah S, Smart SC, Trento A, Siegel RJ, et al. Randomized comparison of percutaneous repair and surgery for mitral regurgitation. 5-Year results of EVEREST II. J Am Coll Cardiol. 2015 Dec 29;66(25):2844-54.

24. Ponikowski P, Voors AA, Anker SD, Bueno H, Cleland JG, Coats AJ, et al. 2016 ESC Guidelines for the diagnosis and treatment of acute and chronic heart failure: The Task Force for the diagnosis and treatment of acute and chronic heart failure of the European Society of Cardiology (ESC). Eur J Heart Fail. 2016 Aug;18(8):891975.

25. Vinereanu D, Bleasdale R, Turner M, Frenneaux MP, Fraser AG. Comparison of left ventricular-biventricular pacing on ventricular synchrony, mitral regurgitation, and global left ventricular function in patients with severe chronic heart failure. Am J Cardiol. 2004 Aug 15;94(4):519-21.

26. Vinereanu D, Turner MS, Bleasdale RA, Mumfors CE, Cinteza M, Frenneaux MP, et al. Mechanisms of reduction of mitral regurgitation by cardiac resynchronization therapy. J Am Soc Echocardiogr. 2007 Jan;20(1):54-62.

27. Vinereanu D. Mitral regurgitation and cardiac resynchronization therapy. Echocardiography. 2008 Nov;25(10):1155-66.

28. Van Bommel RJ, Marsan NA, Delgado V, Borleffs CJW, van Rijnsoever EPM, Schalij MJ, Bax JJ. Cardiac resynchronization therapy as a therapeutic option in patients with moderate-severe functional mitral regurgitation and high operative risk. Circulation. 2011 Aug 23; 124(8):912-9. 